\title{
LA MODIFICACIÓN DE MEDIDAS DICTADAS EN SENTENCIA EXTRANJERA: UNA CUESTIÓN PENDIENTE (AP CANTABRIA 11 FEBRERO 2020)
}

\author{
THE AMENDMENT OF MEASURES ISSUED IN A FOREIGN \\ JUDGMENT: A PENDING QUESTION \\ (AP CANTABRIA, FEBRUARY 11, 2020)
}

\author{
Yolanda Dutrey GuANTES \\ Profesora Titular Derecho internacional privado \\ Universidad Rey Juan Carlos
}

Recibido: 15.11.2020 / Aceptado: 14.12.2020

DOI: https://doi.org/10.20318/cdt.2021.5994

\begin{abstract}
Resumen: La modificación de sentencias dictadas en países extranjeros sigue siendo una cuestión que no está definitivamente resuelta por nuestros tribunales. Hay dos cuestiones problemáticas. La primera de ellas es la duda acerca de la necesidad de solicitud de exequatur previo a la modificación de las medidas recogidas en una sentencia extranjera. La segunda es la falta de aplicación de las normas de competencia judicial internacional y su sustitución por normas de competencia judicial interna. Este auto muestra otra confusión que es otorgar la competencia para modificar las medidas de una sentencia extranjera al juez que dictó el exequatur.
\end{abstract}

Palabras clave: divorcio notarial, modificación de medidas, competencia internacional, reconocimiento incidental, exequatur.

\footnotetext{
Abstract: The amendment of judgments handed down in foreign countries is an issue that has not yet been definitively resolved by our Courts. There are two troubling questions that are repeated over time. The first one is the requirement or not of exequatur prior to the amendment of the foreign judgment. The second problem is the lack of application of the rules of international jurisdiction and their replacement by rules of domestic jurisdiction. This Order shows another confusing variable, pointing out that international jurisdiction to modify a judgment belongs to the judge who recognized the full effectiveness of the foreign divorce resolution, that is, the judge who pronounced the exequatur.

Keywords: notarial divorce, modification of measures, international jurisdiction, incidental recognition, exequatur.

Sumario: I.- Antecedentes de hecho: modificación de medidas recogidas en divorcio notarial II.- El exequatur de los divorcios notariales: una cuestión ya superada III.- Cuestiones problemáticas que aún persisten en la modificación de sentencias 1.- La necesidad de exequatur previo y la mala comprensión del reconocimiento incidental 2.- La utilización de normas de competencia judicial interna para atribuir competencia judicial internacional IV.- La necesaria aplicación de las normas de competencia judicial internacional III.- Conclusión: demasiados años a vueltas con el mismo tema.
} 


\section{Antecedentes de hecho: modificación de medidas recogidas en divorcio notarial}

1. El auto comentado se dicta en respuesta a la solicitud de modificación de una escritura de divorcio de mutuo acuerdo otorgada por notario colombiano que obtuvo el exequatur por auto dictado el 17 de febrero de 2014. El exequatur del divorcio notarial colombiano lo dictó el Juez de primera instancia núm. 9 de Santander, acordando el reconocimiento y ejecución de la resolución de divorcio. Nótese que en Colombia el divorcio notarial puede realizarse aunque haya menores de edad. Años más tarde, se solicita la modificación de las medidas previstas en el divorcio notarial, para lo que el Juez de primera instancia de Santander se declara incompetente. No se dice de manera expresa el motivo jurídico de la incompetencia pero suponemos que obedece, como en otros muchos autos, a que el Juez de primera instancia de Santander no es el juez que dictó la resolución.

2. La AP de Cantabria corrige el fallo y señala la competencia de los tribunales de Santander para conocer de la modificación de las medidas recogidas en el documento notarial colombiano. El resultado al que llega la AP es el correcto pero no la vía que utiliza. Considera que el tribunal es competente en base a las normas de competencia interna de la LEC y atribuye también competencia al Juez que dictó el exequatur para modificar la sentencia que fue reconocida, a pesar de que no hay ninguna norma en el ordenamiento jurídico español que considere al juez que dictó el exequatur competente para modificar lo reconocido.

3. La modificación de medidas de sentencias extranjeras es frecuente en nuestros juzgados ${ }^{1} \mathrm{y}$, hoy en día, existen soluciones legales y jurisprudenciales claras por lo estas dilaciones indebidas ya no deberían producirse.

\section{El exequatur de los divorcios notariales: una cuestión ya superada}

4. El exequatur de escrituras notariales de divorcio ha sido una materia con luces y sombras y aunque sigue habiendo algún auto relativamente reciente que se opone al exequatur de divorcio notarial, ${ }^{2}$ ya es una cuestión aclarada.

5. Hay tres factores que han contribuido a esta claridad: la jurisprudencia consolidada del TS, el concepto amplio de tribunal que está en todos los puntos de nuestro ordenamiento (comunitario o no) y la ley de jurisdicción voluntaria que recoge el divorcio notarial.

6. En primer lugar, señalamos que el TS lleva años admitiendo el exequatur de divorcios notariales. Por ejemplo, el ATS de 23 de febrero de 1999 admitía el exequatur de una escritura notarial otorgada en Cuba por la que se disponía el divorcio entre las partes señalando que la intervención del Notario no se limita a funciones fedatarias sino que se le atribuyen competencias en orden a la comprobación de determinadas condiciones (...) lo cual posibilita el reconocimiento de la escritura notarial que lo declara ${ }^{3}$.

\footnotetext{
${ }^{1}$ La gran cantidad de procedimientos de modificación de medidas recogidas en sentencias extranjeras es puesta de manifiesto por P. PEITEADO MARISCAL, "Procesos transfronterizos de modificación de medidas, residencia habitual del menor y competencia interna de los tribunales españoles", $C D T, 12,2,2020$, pp. 1358-1385

${ }^{2}$ Vid. auto de 14 de marzo de 2019 dictado por el Juzgado de Primera Instancia de Vitoria-Gasteiz, Procedimiento Exequatur $\mathrm{n}^{\circ} 335 / 19$ : en este auto se inadmite a trámite una demanda de exequatur en la que se solicitaba el reconocimiento de una escritura de divorcio notarial colombiana. El auto fue corregido por la AP de Álava que señala en auto de 8 de julio de 2019 que cabe el exequatur de un documento notarial donde se acuerda el divorcio y se procede a la liquidación ganancial, toda vez que en Colombia está equiparado el divorcio judicial con el Divorcio notarial.

${ }^{3}$ En sentido similar ATS 2 de julio de 1996, 16 de julio de 1996, 19 de noviembre de 1996, 4 de febrero de 1997 y 24 de junio de 1997, entre otros muchos.
} 
7. En segundo lugar, se ha instalado en nuestro ordenamiento un concepto amplio de tribunal, incorporado desde el principio por el derecho comunitario ${ }^{4}$ que incluye a los notarios. En las sentencias procedentes de terceros Estados, es la Ley de cooperación jurídica internacional en materia civil (en adelante LCJIC) ${ }^{5}$ la que ha incorporado este concepto amplio en su art. 43.c) $)^{6}$ dentro del título V correspondiente al exequatur, eliminando cualquier duda que pudiera plantearse acerca del reconocimiento de divorcios notariales válidamente dictados en el Estado de procedencia.

8. En tercer lugar, la Ley de Jurisdicción voluntaria (en adelante LJV) ${ }^{7}$, ha influido también en esta cuestión; ahora podemos tener divorcios notariales (art. $54 \mathrm{JVV}$ ), por lo que no se puede restringir la eficacia de un divorcio notarial dictado en el extranjero. Nótese que, aunque este argumento tenga su peso, el divorcio notarial de Colombia no es equiparable al español ya que los notarios pueden declararlo aunque existan hijos menores ${ }^{8}$.

9. En el auto comentado, el divorcio notarial cuya modificación se solicita había sido reconocido por los tribunales españoles.

\section{Cuestiones problemáticas que aún persisten en la modificación de sentencias}

10. La cuestión recurrida ante la Audiencia Provincial es la declaración de incompetencia del Juez de primera instancia de Santander para conocer de la modificación de las medidas (dictadas en el documento notarial y reconocidas previamente en España). Los tribunales españoles tradicionalmente han alegado dos cuestiones para declararse incompetentes en la materia de modificación de medidas: que la sentencia tenía que ser previamente reconocida para ser modificada y que la competencia para modificar una sentencia es del juez que la dictó.

\section{La necesidad de exequatur previo y la mala comprensión del reconocimiento incidental}

11. La primera cuestión, la necesidad de que la sentencia extranjera sea reconocida en España (obtenga el exequatur) antes de proceder a su modificación, ha sido tratada en numerosas ocasiones por la doctrina y la jurisprudencia.

12. Ya en el año 2000 , el TC dictó la sentencia la $16 / 2000^{9}$ como consecuencia de un procedimiento de modificación de medidas en el que el Juez de primera instancia se había declarado incompetente porque (entre otras cuestiones) "la resolución que se pretende no tiene reconocida eficacia civil en España”, es decir, porque la sentencia no había pasado por el procedimiento previo de exequatur. La declaración de incompetencia fue corregida por el TC.

${ }^{4}$ Vid. Definición de órgano jurisdiccional y de juez en el art. 2 del Reglamento 2201/2003.

${ }^{5}$ Ley 29/2015 de 30 de julio, BOE núm. 182, de 31 de julio de 2015.

${ }^{6}$ Artículo 43. Definiciones. A los efectos de este título se entenderá por: c) Órgano jurisdiccional: toda autoridad judicial o toda autoridad que tenga atribuciones análogas a las de las autoridades judiciales de un Estado, con competencia en las materias propias de esta ley.

${ }^{7}$ Ley 15/2015, de 2 de julio, BOE núm. 158 de 3 de julio de 2015

${ }^{8}$ Colombia es un ordenamiento (Ley colombiana 962 de 2005) conforme al cual es posible realizar divorcio notarial aun en el caso de que el matrimonio tenga hijos menores. Si existen hijos menores intervendrá un "Defensor de Familia" al que se le notificará el acuerdo al que han llegado los cónyuges con el objeto de que controle que lo convenido cumple con la protección necesaria de los hijos menores de edad. Vid acerca del divorcio notarial en Latinoamérica http://192.188.52.94/ bitstream/3317/14123/1/T-UCSG-POS-DDNR-36.pdf

${ }^{9}$ Sentencia 61/2000, de 13 de marzo, (BOE núm. 90, de 14 de abril de 2000). Vid. al respecto, I. Heredia Cervantes, "Competencia de los tribunales españoles para modificar decisiones judiciales extranjeras (Comentario a la STC 61/2000, de 13 de marzo)", Derecho Privado y Constitución Núm. 14. Enero-Diciembre 2000, pp. 185-205; CARBALLO PIÑERO, L. "Competencia judicial internacional y modificación de prestaciones de ejecución continuada: más allá de la STC 61/2000", $A E D I P r$, t. I, 2001, pp. 463-482 
13. Entre otros muchos ejemplos, años más tarde, la AP Madrid en auto de 30 de noviembre de 2005 se pronuncia en un supuesto similar de modificación de medidas recogidas en sentencia ecuatoria$\mathrm{na}^{10}$. En dicho auto, la AP de Madrid se declara incompetente porque no se ha solicitado el exequatur de la sentencia extranjera.

14. Muchos fueron los comentarios de la doctrina española acerca de esta situación jurídica y de la necesidad de su modificación. Se constató la incongruencia de solicitar el exequatur de una sentencia cuyos efectos querían modificarse así como la inconveniencia de retrasar los procedimientos de modificación de medidas (normalmente referentes a menores y alimentos) con expedientes jurídicos carentes de efecto e interés.

15. Las soluciones barajadas para modificar sentencias extranjeras eran tres: la solicitud del exequatur, el reconocimiento incidental y la solicitud ex novo de las medidas presentando la sentencia extranjera como documento probatorio ${ }^{11}$. Las soluciones jurisprudenciales eran de lo más variado exigiendo en ocasiones el exequatur o no, según considerase oportuno el tribunal.

16. Todas estas soluciones han sido incorporadas en el art. 45 de la $\mathrm{LCJIC}^{12}$ que señala que las resoluciones extranjeras firmes o definitivas que se refieran a materias que por su propia naturaleza son susceptibles de ser modificadas (como por ejemplo las prestaciones de alimentos, las decisiones sobre la guarda y custodia de menores o las medidas de protección de menores e incapaces) podrán ser modificadas previo su reconocimiento a título principal (procedimiento de exequatur) del art. $52 \mathrm{y} \mathrm{ss} \mathrm{LCJIC}$ o incidental del art. $44.2 \mathrm{LCJIC}^{13}$. Esta disposición no impide que se pueda plantear una nueva demanda en un proceso declarativo ante los órganos jurisdiccionales españoles, correspondiendo, en definitiva, a las partes optar bien por la modificación de la sentencia extranjera (tras el exequatur, con un reconocimiento incidental) bien por la apertura de un nuevo procedimiento ${ }^{14}$.

17. La incorporación del reconocimiento incidental es muy clara y además es una técnica incorporada hace mucho por los Reglamentos de la Unión Europea. En la LCJIC este tipo de reconocimiento se recoge, como hemos señalado, en el art. 44.2 LCJIC y exime del largo procedimiento de exequatur que además no tiene ningún sentido si no se pretende reconocer los efectos de la sentencia si no modificarlos.

18. A pesar de esta claridad legal, en ocasiones, nuestros tribunales siguen mostrando falta de comprensión de este reconocimiento incidental y requiriendo el exequatur previo. El auto dictado por el Juzgado de Primera Instancia de la Almunia de Doña Godina ${ }^{15}$ inadmite a trámite una demanda de modificación de medidas al no constar que la sentencia a modificar haya sido reconocida por los Tri-

${ }^{10}$ Vid. Y. Dutrey Guantes, “Comentario al AAP de Madrid de 30 de noviembre de 2005”, REDI, 2006, Vol. 58, Número 1, pp. 477-481.

${ }^{11}$ Vid. S. Álvarez González, Crisis matrimoniales internacionales y prestaciones alimenticias entre cónyuges, Madrid, Civitas, 1996, p. 227 y ss. Más artículos y comentarios de la época se pueden ver citados en Y. Dutrey GuANTEs, "La modificación de las medidas acordadas en sentencias de divorcio extranjeras", El Derecho on line, ref.: EDB 2006/102720

${ }^{12}$ Artículo 45. Resoluciones extranjeras susceptibles de modificación. 1. Una resolución extranjera podrá ser modificada por los órganos jurisdiccionales españoles siempre que hubiera obtenido previamente su reconocimiento por vía principal o incidental con arreglo a las disposiciones de este título. 2. Esto no impedirá que se pueda plantear una nueva demanda en un procedimiento declarativo ante los órganos jurisdiccionales españoles. Vid. igualmente el preámbulo de la Ley.

${ }^{13}$ Artículo 44 LCJIC. Reconocimiento. 2. Cuando el reconocimiento de una resolución extranjera se plantee de forma incidental en un procedimiento judicial, el juez que conozca del mismo deberá pronunciarse respecto a dicho reconocimiento en el seno de cada procedimiento judicial según lo dispuesto en las leyes procesales. La eficacia del reconocimiento incidental quedará limitada a lo resuelto en el proceso principal y no impedirá que se solicite el exequátur de la resolución extranjera

${ }^{14} \mathrm{Vid}$. para más información acerca de estos artículos, A. L. Calvo Caravaca/ J.CARrascosa González, Comentario a la Ley 29/2015 de cooperación jurídica internacional en materia civil, "artículo 44 y Artículo 45", A. FeRnÁNDEZ TRESGUERRES, (coord.), Bosch, 2017, pp. 384-392

${ }^{15}$ Este auto ha sido corregido por la AP de Zaragoza de 28 de noviembre de 2017, no 765/2017 
bunales españoles ${ }^{16}$. La Audiencia Provincial de Zaragoza señala que no hace falta exequatur porque el reconocimiento necesario para modificar la sentencia puede ser el incidental.

19. Esta falta de comprensión del reconocimiento incidental previsto en el art. 44.2 LCJIC citado puede observarse en actuaciones judiciales muy recientes. En el auto de la AP de Barcelona de 29 de mayo de $2020^{17}$ el demandante solicita en el mismo escrito de demanda el reconocimiento de efectos civiles de sentencia dictada en el extranjero y la modificación de medidas definitivas adoptadas en dicha resolución.

20. El juez de primera instancia, en lugar de modificar la sentencia utilizando el reconocimiento incidental (arts. 44.2 y 45 LCJIC), dicta un exequatur (arts. 52 y ss LCJIC), manda inscribir en el Registro el divorcio e insta a las partes a que soliciten en otro procedimiento la modificación de medidas. La AP de Barcelona ratifica el auto a pesar de que parece claro que el procedimiento principal era el de modificación de medidas ${ }^{18}$ y no de el de reconocimiento que, por otro lado, en caso de que fuera un exequatur, solo sería acumulable a la petición de ejecución en el mismo escrito ${ }^{19}$.

21. En el auto de la AP de Cantabria comentado, esta cuestión que tratamos (la necesidad de exequatur previo a la modificación de la sentencia extranjera) no se aborda porque el exequatur había sido reconocido tiempo atrás. No obstante, del tenor literal del texto se desprende que la necesidad de exequatur sigue siendo una condición requerida. Señala el auto: "al ser plenamente eficaz en nuestro ordenamiento la resolución extranjera por haber sido reconocida bajo el trámite del exequatur ..." Esta afirmación trasluce que aún sigue presente el binomio "modificación-exequatur" entre nuestra jurisprudencia y nos hace preguntarnos qué hubiera ocurrido si la sentencia no hubiera obtenido el exequatur años atrás.

22. En todo caso, lo que puede deducirse con claridad de todas estas actuaciones es que la distinción entre exequatur y reconocimiento incidental no está aún clara cinco años después de ver la luz la Ley $29 / 2015$.

\section{La utilización de normas de competencia judicial interna para atribuir competencia judicial internacional}

23. La segunda cuestión confusa en la materia de modificación de medidas con elemento extranjero es la declaración de incompetencia del juez utilizando normas de competencia interna, en lugar de normas de competencia judicial internacional.

${ }^{16}$ También se declara incompetente dado que el art. 775 LEC dispone que la modificación de medidas debe ser solicitada ante el Tribunal que las acordó, cuestión que será comentada en el apartado siguiente.

${ }^{17}$ AAP Barcelona de 29 de mayo de 2020 (sección 12), n 148/2020

${ }^{18}$ Los procedimientos de modificación de medidas no son un apéndice de otro proceso sino que implican plenas posibilidades de alegación y de prueba, plenas facultades procesales tanto para las partes como para el tribunal $C f$. P. PeITEAdo MARISCAL, "Procesos transfronterizos...", Cuadernos de derecho transnacional, Vol. 12, n 2, 2020, págs. 1364- 1365

${ }^{19}$ Este es un auto complejo que bien merecería un comentario aparte para el que haría falta el escrito de demanda y algún dato más del procedimiento: el demandante solicita reconocimiento de sentencia extranjera y modificación de medidas de manera acumulada. El juzgado de primera instancia admite a trámite la demanda sobre reconocimiento de sentencia extranjera de divorcio conforme al art. 52 LCJIC. El demandante no recurre dicha admisión -no hay inadmisión de la demanda de modificación de medidas- y el Juez dicta auto acordando la inscripción del divorcio en el Registro Civil y señalando que la modificación de medidas deberá cursarse mediante una demanda nueva. Es decir, otorga el exequatur y deja sin resolver la petición de modificación de medidas, instando a las partes a iniciar un nuevo procedimiento.

La AP de Barcelona confirma el auto y señala que "la solicitud de reconocimiento de efectos civiles de la sentencia extranjera se plantea como principal y no como incidental de un procedimiento de modificación de determinadas medidas definitivas, aun cuando manifiesta acumular ambas acciones". Si el demandante manifiesta acumular acciones, parece claro que nos encontramos en el art. $44.2^{\circ}$ LCJIC (reconocimiento incidental) dado que la acción de exequatur únicamente es acumulable a la solicitud de ejecución de la sentencia (art. 54 LCJIC). En todo caso, no se respeta la tutela judicial efectiva al no conocer de la modificación de medidas solicitada. 
24. Son muchas y de gran relevancia las sentencias que ya han zanjado esta cuestión, por lo que no deberían nuestros tribunales declararse incompetentes para modificar las sentencias en base a normas de competencia funcional, en ningún caso.

25. En la importante sentencia del TC $61 / 2000$ ya citada, el tribunal de primera instancia se declaró incompetente porque "para la legislación española es cuestión de orden público que la modificación de las medidas derivadas de separación o divorcio le corresponde al Juez que las dictó". El TC aclaró que esa norma (art. 55 LEC, ahora el art. 775 LEC) era una norma de competencia interna ajena al supuesto que se planteaba. Señala la STC que las resoluciones del Juzgado y de la Audiencia Provincial pronunciaron una "falta de competencia" que no se apoya en regla alguna de competencia judicial internacional, sino en una simple regla relativa a la competencia funcional. Al negarse a conocer de la demanda presentada fundándose en una regla de competencia funcional, denegaron el acceso a la jurisdicción aplicando una norma ajena a la decisión adoptada.

26. El TJUE ha tratado también este tema en sentencia de 15 de febrero de $2017^{20}$ donde señala que "los órganos jurisdiccionales de un Estado miembro que han adoptado una resolución firme en materia de responsabilidad parental y de obligaciones de alimentos, en lo que respecta a un menor de edad, no siguen siendo competentes para conocer de una demanda de modificación de las medidas establecidas en esa resolución en el caso de que la residencia habitual del menor esté situada en el territorio de otro Estado miembro. Los órganos jurisdiccionales competentes para conocer de esa demanda son los órganos jurisdiccionales de este último Estado miembro". Es decir, la competencia es del Juez que señalan los Reglamentos y no del que dictó la Resolución que se va a modificar.

27. El TS también se ha pronunciado en auto de 17 septiembre $2019^{21}$ en un procedimiento de modificación de medidas sobre lo dispuesto en el art.775 LEC señalando que esta es una norma de competencia interna y no altera, en ningún caso, las mencionadas normas de competencia judicial internacional. La modificación que en España ha habido del art. 775 LEC no alterna en nada la competencia judicial internacional prevista en las normas de competencia judicial internacional. Sigue siendo una norma de competencia interna ${ }^{22}$, aunque ha contribuido a incrementar, aún más la confusión en el ámbito internacional.

28. En el auto de Cantabria comentado en primera instancia, a pesar de que todas las partes residen en España, el Juez de primera instancia se declara incompetente. Sin ninguna mención a ninguna norma de competencia judicial internacional, la AP de Cantabria señala que "En consecuencia, al ser plenamente eficaz en nuestro Estado la resolución extranjera por haber sido reconocida bajo el trámite del exequatur, la posibilidad de su modificación en España deviene de la aplicación del citado art. 45 (LCJIC), a cuyo efecto será necesario seguir las reglas imperativas de competencia previstas en el art. 769 LEC para la atribución del actual asunto. En consecuencia, corresponde al juzgado $n^{\circ} 9$ de Santander que dictó la resolución ahora recurrida por ser competente de acuerdo al art. 769 LECresidencia de la demandada en Santander-, al igual que el actor -en relación con el art. 775 LEC- (ya que) el juzgado $n^{\circ} 9$ de Santander fue quien reconoció la plena eficacia en España de la resolución de

\footnotetext{
${ }^{20}$ ECLI:EU: C:2017:118

${ }^{21}$ ATS de 17 septiembre 2019 [ECLI:ES: TS:2019:9225A]. Vid. comentario de esta sentencia en M.J. Valverde MartíneZ, "Competencia en la modificación por tribunales españoles de medidas relativas a alimentos establecidas por tribunales extranjeros. Comentario al auto del TS de 17 de septiembre”, CDT, 12, 1, 2020, pp. 763-775

${ }^{22}$ ATS 17 de septiembre 2019, Fundamento TERCERO.- A la vista de lo expuesto, determinada la competencia internacional de los órganos jurisdiccionales españoles para el conocimiento del asunto ( art. 3 b) del Reglamento (CE) 4/2009, de 18 de diciembre de 2008 ), y la imposibilidad de aplicar el art. 775 LEC al supuesto de autos, al haber sido dictada la sentencia de divorcio por un órgano jurisdiccional de Rumanía, procede resolver el presente conflicto de competencia, de acuerdo con el informe del Ministerio Fiscal, atribuyendo la competencia para el conocimiento del asunto al Juzgado de Primera instancia $n^{\circ}$ 7 de DIRECCION001, al hallarse en esa ciudad el domicilio de la menor, en aplicación del art. 769.3 LEC, de acuerdo con los criterios expuestos y seguidos por esta sala hasta la modificación del art. 775 LEC por la Ley 42/2015, de 5 de octubre.
} 
divorcio extranjera". Es decir, la competencia judicial internacional, según la AP, viene atribuida por el art. 769 y por el art. 775 LEC.

29. Por tanto, se atribuye competencia a los jueces españoles en base a normas de competencia territorial en materia de procesos matrimoniales y de menores, una cuestión recurrente en nuestros juzgados a pesar de la existencia de la importante jurisprudencia que hemos señalado, pero, además, se añade otra cuestión no solo confusa sino también errónea, ya que considera que es competente el Juez que dictó el exequatur y ello en base al art. 775 LEC. Como no puede atribuirse competencia al Juez que dictó la sentencia (obviamente porque es extranjero), entonces se atribuye competencia al Juez que dictó el exequatur. La AP equipara dictar sentencia con otorgar el exequatur de la sentencia para atribuir competencia al juzgado conforme al art. 775 LEC.

30. Esta argumentación es sorprendente, no solo porque prescinde del dato de que el exequatur no es necesario para la modificación si no, y sobre todo, porque no hay ninguna norma de competencia judicial internacional que atribuya competencia al juez del exequatur para modificar la sentencia extranjera que reconoció. El binomio modificación-exequatur aparece de nuevo.

31. Es evidente que no se entiende la base y es que a la modificación de sentencias se le aplican las normas de competencia judicial internacional por razón de la materia y no entra en juego ni el juez que dictó la sentencia ni el juez que dictó el exequatur, ni el juez al que atribuyen competencia las normas territoriales. Ni quien dicta la sentencia extranjera, ni quien la homologa repercute en los criterios de competencia judicial internacional.

\section{La necesaria aplicación de las normas de competencia judicial internacional}

32. Aunque finalmente el resultado es el mismo, el auto comentado del Juzgado de primera instancia de Santander, así como el de la AP de Cantabria, deberían atribuir competencia a los tribunales españoles por los Reglamentos comunitarios, que atienden a la naturaleza de las pretensiones y no a su vinculación con procesos previos ${ }^{23}$. La competencia judicial internacional es previa a la competencia territorial y tiene que quedar aclarada ya que puede haber supuestos donde los resultados no coincidan.

33. Como el hijo común, tal y como se menciona, es mayor de edad, suponemos que se solicita la modificación de los alimentos. La competencia, por tanto, les corresponde a los tribunales españoles en virtud del art. 3 a) o b) del Reglamento 4/2009. El art. 3.a) atribuye competencia a los tribunales del lugar donde el demandado tenga su residencia habitual y el apartado b) al juez donde el acreedor tenga su residencia habitual ${ }^{24}$.

34. Como en muchas otras ocasiones, la situación fluye porque el resultado no varía, ya que según el texto del auto todas las partes implicadas residen en Santander coincidiendo todas las normas de competencia judicial internacional y todas las de competencia territorial en el mismo sitio ${ }^{25}$.

35. En todo caso, parece que no está aún claro que en nuestro país existe un sistema autónomo de normas de competencia judicial internacional que impide la atribución de competencia internacional en base a normas procesales territoriales.

\footnotetext{
${ }^{23}$ Vid. P. Peiteado Mariscal, "Procesos transfronterizos...”, Cuadernos de derecho transnacional, Vol. 12, №. 2,2020 pág. 1365

${ }^{24}$ Aunque hay un artículo específico en el Reglamento 4/2009 que hace referencia concreta a la modificación de sentencias, no es aplicable en este supuesto, dado que el acreedor de alimentos reside en España. Vid. M. A. RodríGEz Vázquez, "La regulación del Reglamento 4/2009 en materia de obligaciones de alimentos", Revista electrónica de estudios internacionales (REEI), $\mathrm{n}^{\circ} .19$, 2010, p. 15

${ }^{25}$ Cabe preguntarse, incluso, si al tratase de alimentos de un hijo mayor, el art. 769 LEC sería el artículo aplicable de manera territorial, pero eso sería objeto de un estudio distinto que excede la materia aquí tratada.
} 


\section{Conclusión: demasiados años a vueltas con el mismo tema}

36. Son ya muchos los años que estas cuestiones llevan perjudicando los derechos de los particulares, retrasando procedimientos de menores generalmente acompañados de alimentos por una pura incomprensión técnica. Esto no parece de recibo en materias donde la protección y la rapidez son requisitos necesarios para la consecución de la Justicia.

37. La cuestión es sencilla. No hace falta exequatur para modificar una sentencia. Puede realizarse la modificación con exequatur previo, con reconocimiento incidental o a través de un procedimiento declarativo ex novo. Todas estas variables ya se manejaban antes de la reforma por la doctrina; ahora están en la Ley, por lo que no deberían seguir generando confusión.

38. Teniendo en cuenta el párrafo anterior, los tribunales españoles tendrán competencia si se cumplen los criterios de competencia judicial internacional, que son los que marcan los Reglamentos, los Convenios y en su defecto el art. 22 LOPJ, no dependiendo la competencia de las normas territoriales dado que existe un sistema autónomo de competencia judicial internacional. Lo ha señalado el TC, el TJUE y el TS por lo que tampoco debería esta cuestión seguir generando confusión.

39. Los arts. 769 y 755 LEC son artículos de competencia interna, tal y como señaló ya el TC en el año 2000 y ha señalado el TS, por lo que no pueden ser utilizados por nuestros jueces para declararse ni competentes, ni incompetentes sustituyendo a las normas de competencia judicial internacional.

40. Por otro lado, haber dictado el exequatur tampoco es un criterio de competencia judicial internacional para modificar la sentencia reconocida. Esta interpretación extensiva e injustificada del art. 775 LEC se aleja del tenor literal de la norma e identifica al tribunal que acordó las medidas definitivas en el extranjero con el que dictó el reconocimiento de las mismas en España.

41. Esta última y reciente interpretación del 775 LEC, junto con todos los aspectos comentados, muestra que existen, todavía, algunas lagunas sobre cuestiones básicas de Derecho internacional privado. 